Proceedings of the Institution of
Civil Engineers
Bridge Engineering 163
December 2010 Issue BE4
Pages $213-224$
doi: $10.1680 /$ bren.2010.4.213
Paper 900034
Received 29/09/2009
Accepted 20/08/2010
Keywords:
bridges/models(physical)/wind
loading \& aerodynamics
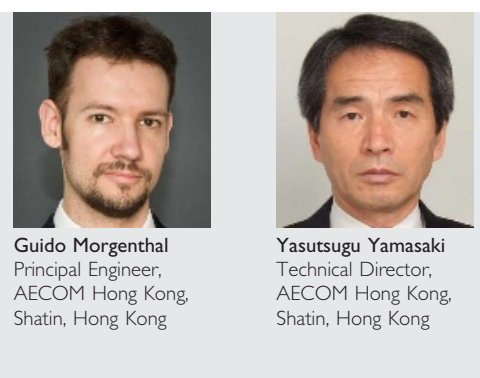

\title{
Behaviour of very long cable-stayed bridges during erection
}

G. Morgenthal Dipl.-Ing., MSc, MPhil, PhD, CEng, MICE and Y. Yamasaki MSc

\begin{abstract}
Stonecutters Bridge and Sutong Bridge in China have pushed the world record for main span length of cablestayed bridges to over $1000 \mathrm{~m}$. The design of these bridges, both located in typhoon-prone regions, was strongly influenced by wind effects during erection. Rigorous wind tunnel test programmes were devised and executed to determine the aerodynamic behaviour of the structures in the most critical erection conditions. Testing was augmented by analytical and numerical analyses to verify the safety of the structures throughout construction and to ensure that no serviceability problems would affect the erection process. This paper outlines the wind properties assumed for the bridge sites, the experimental test programme with some of its results, the dynamic properties of the bridges during free-cantilevering erection and an assessment of their aerodynamic performance. The similarities and some revealing differences between the two bridges in terms of their dynamic response to wind action are also discussed.
\end{abstract}

\section{INTRODUCTION}

Two new cable-stayed bridges in China have surpassed the current world record in main span length by breaking into the realm of over $1000 \mathrm{~m}$ span. Sutong Bridge sets the new record at $1088 \mathrm{~m}$ span, with Stonecutters Bridge following at $1018 \mathrm{~m}$ (Figure 1). Figure 2 shows the bridges during free-cantilevering erection. Sutong Bridge, which is the key element of a large crossing over the Yangtze River, features a conventional layout (Figure 3) with A-shaped towers and an all-steel superstructure with regular backspans. Stonecutters Bridge, located in the urban area of Hong Kong and hence subject to geometrical constraints, has very short backspans made of concrete to balance the long steel main span. It further features single-pole towers (Figure 4) and a twin-box grillage deck (Figure 5), making it a rather unusual configuration.

The bridge main spans were erected by traditional cantilevering methods with prefabricated steel segments (Morgenthal et al., 2010) (Figure 2). Maunsell AECOM was responsible for the comprehensive construction engineering services for both projects. Besides many other strands of work, this included extensive studies on the aerodynamic behaviour of the bridges during construction. The scope for wind tunnel testing was proposed and detailed test briefs were developed. The implementation of the tests was supervised and the results processed to determine the basic aerodynamic properties of various bridge components as well as to quantify the dynamic bridge response to a number of wind excitation phenomena. Numerical analyses were conducted to supplement the wind tunnel testing and to study construction situations not directly tested in the tunnel.

The impact of wind on slender structures like long-span bridges can be manifold. Aerodynamic stability is a limit-state criterion that needs to be carefully checked to ensure structural integrity. Serviceability issues may arise from the effects that vortex shedding from the deck, tower or cables may have on the structure. Cable vibrations can arise from further mechanisms such as the combined effects of rain and wind.

In a natural wind environment that is subject to turbulence inherent in the atmospheric boundary layer, there are virtually no static wind effects. The structural adequacy of bridge components is traditionally checked to static wind loads but, with highly flexible structures, the structural demand is often dominated by the dynamic response. Gust factors used to represent the stochastic distribution of wind speeds and to derive equivalent static load cases are of limited use as they fail to adequately account for such dynamic response. This paper discusses a rigorous approach to modelling the buffeting response where the full dynamic response of the bridge is represented in the analysis.

\section{DESIGN WIND SPECIFICATIONS}

Suitable design criteria need to be established as the basis for an analysis of the adequacy of a partially erected bridge under wind loads. Design wind specifications are used to reflect the wind conditions on site in a probabilistic sense. Owing to its shorter exposure period, the erection condition is generally designed for smaller wind loads than the in-service condition.

The wind characteristics adopted for Sutong Bridge were taken from the Chinese code JTG/T D60-01-2004 (CCHPDRI, 2004) and adjusted according to results of detailed analyses of the local wind climate. For Stonecutters Bridge, a $50 \mathrm{~m}$ high mast was set up at the bridge location and continuous wind readings were taken over a period of over 1 year to determine site-specific wind characteristics.

The Sutong Bridge project, whose design is based on allowable stresses, specified a 100 year return period wind for the in-service condition and a 30 year return period wind for the construction stage. The design specifications for Stonecutters Bridge, however, only 


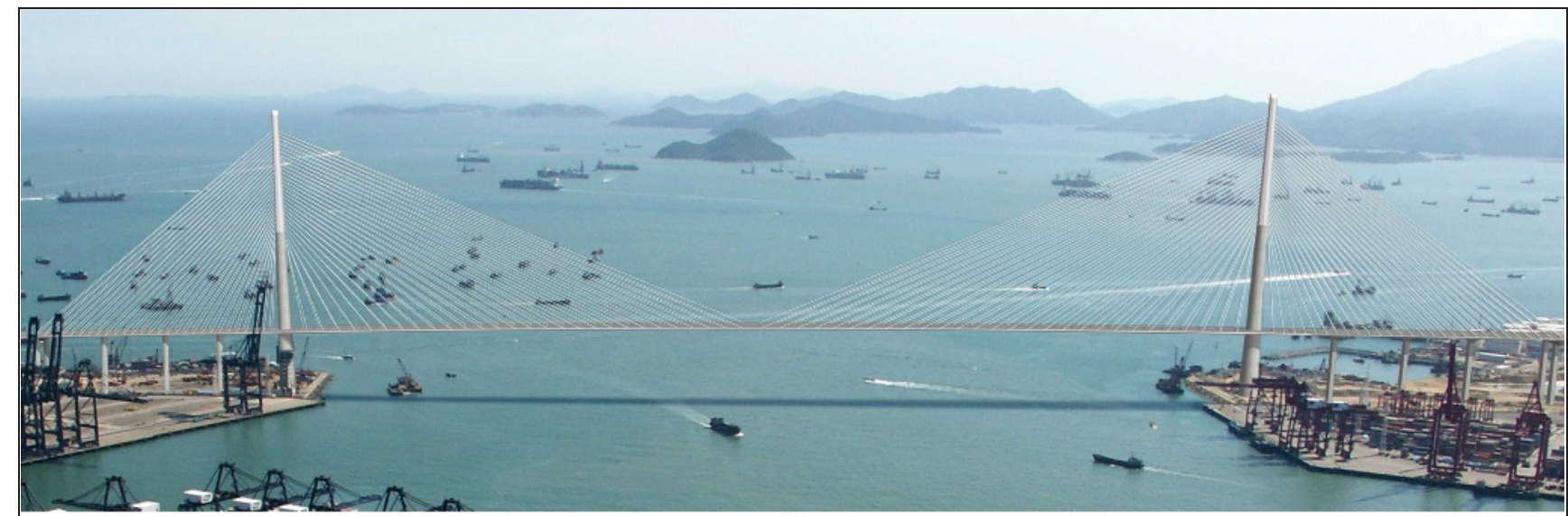

(a)

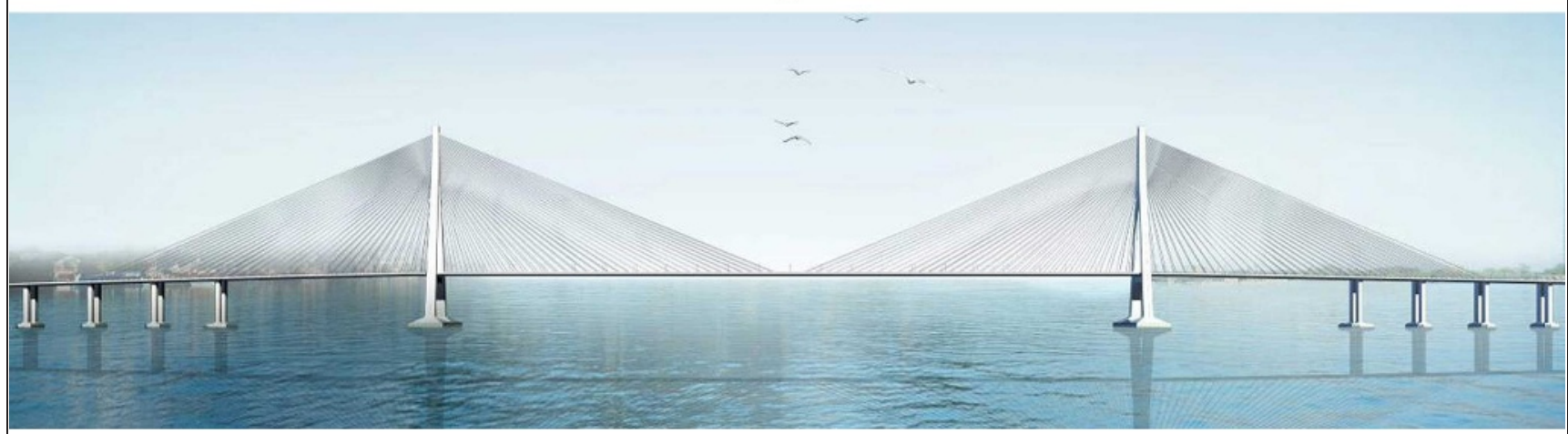

(b)

Figure I. Artists' impressions of the bridges: (a) Stonecutters Bridge and (b) Sutong Bridge

specify one reference wind with a 120 year return period, following the methodology of BS 5400 for bridge design (BSI, 1978). In this limit-state design approach the difference between in-service and erection conditions is accounted for by different load safety factors. While BS 5400 uses safety factors of 1.4 and $1 \cdot 1$ respectively, the design basis of Stonecutters Bridge specifies safety factors of 1.9 and $1 \cdot 2$ in recognition of the different extreme value distribution of wind events in typhoon-prone regions such as Hong Kong. These safety factors were adopted from the government of the Hong Kong Special Administrative Region Structures Design Manual (GHKSAR, 2006).

Figure 6 compares the adopted profiles of wind speed $U$ and turbulence intensity. For Stonecutters Bridge, two different sets of wind properties were devised, namely a land and an ocean fetch scenario corresponding to winds approaching over the mountains and from the sea respectively. The properties for Sutong Bridge are for open-sea conditions. The well-known von Karman wind spectra were used for Stonecutters Bridge; Sutong Bridge used a Kaimai-type spectrum.

\section{WIND TUNNEL TESTING PROGRAMME}

Extensive wind tunnel testing was undertaken for both bridges in order to study their aerodynamic properties. The tests for Stonecutters Bridge were performed at BMT Fluid Mechanics, UK, while those for Sutong Bridge were conducted by Southwest Jiaotong University, China. Stay cable tests for Stonecutters Bridge were carried out at China Aerodynamic Research and Development Centre. Cable testing for Sutong Bridge was undertaken only at the design stage, but not at the construction stage. The design-stage tests had a similar scope to those of the construction-stage Stonecutters Bridge tests. Table 1 gives a summary of the wind tunnel test programmes for both projects.
The section model tests for Stonecutters Bridge were performed for different structural articulations as the aim for the contractor was to optimise drag, mainly because of capacity limitations of the lateral bearing at the tower. Alterations were made to the temporary hand rail and safety toe board. Aeroelastic tests of the section were performed in smooth flow to study vortex-induced vibrations and to establish the aerodynamic stability boundary. Tests for Sutong Bridge were limited to the pre-defined structural configuration with and without the lifting gantry. Again, both smooth and turbulent flow were tested.

Tower aeroelastic tests were undertaken to establish the dynamic response characteristics due to the various aerodynamic excitation mechanisms. Smooth flow tests at low wind speeds were carried out to check sensitivity to vortex-induced vibrations. Tests at higher wind speeds verified that no instabilities were to be expected. Buffeting response was evaluated in a turbulent flow environment. Tests were performed at different angles of incidence, typically in $15^{\circ}$ instances at first with further refinement where the worst-case angle was of importance. For Stonecutters Bridge, the tower was tested with and without equipment whereas only the actual erection configuration with all equipment was tested for Sutong Bridge. Four tower heights were tested for Stonecutters Bridge. Only two configurations - that just before joining of the two tower legs and the full height - were tested for Sutong Bridge.

Aeroelastic tests of the deck construction stages were also conducted. For Stonecutters Bridge, the maximum cantilever stage and a $100 \mathrm{~m}$ shorter cantilever were tested. Sutong Bridge was built in conventional fashion starting with a balanced cantilever construction, the maximum length of which was 


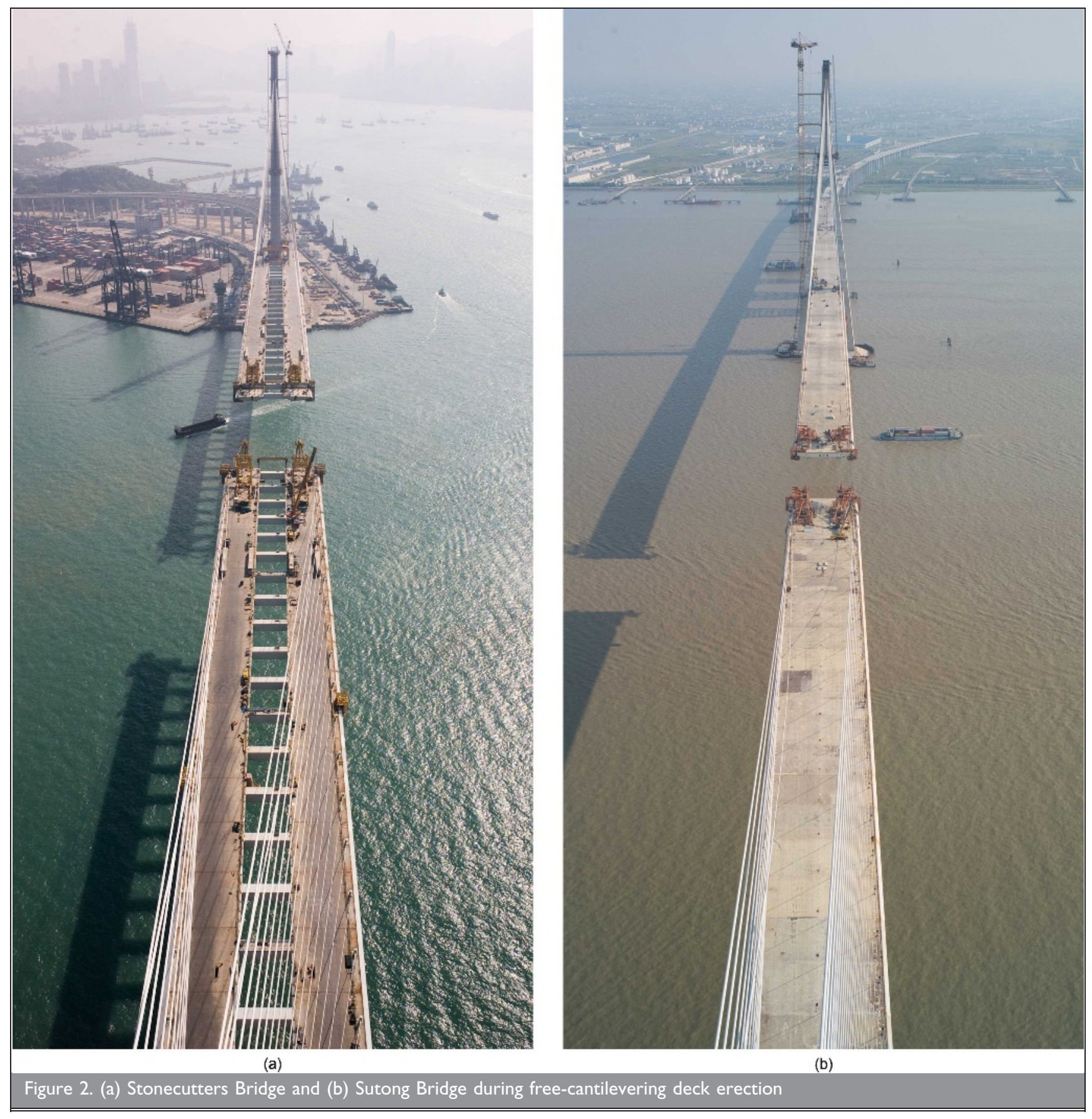

tested first. After backspan closure, the erection proceeded as a single-sided cantilever and the maximum length condition (just before midspan closure) was also tested.

All tests featured a detailed physical representation of structural elements deemed to influence the aerodynamics. Erection articulation, including items such as gantry rail beams, handrails, toe boards, guide vanes and major erection equipment, were replicated.

\section{AERODYNAMIC SECTION PROPERTIES}

Extensive section model tests were performed for both projects, with aerodynamic forces on static cross-sections determined first. The section model tests for Stonecutters Bridge included extensive testing of a number of different configurations. It was realised that the drag of the girder was very sensitive to the temporary hand rail articulation, specifically that of the toe board. A solution was sought where drag loads were acceptable while ensuring the safety of workers. A mesh-type toe board, which reduced obstruction of the airflow but still provided a barrier at foot height, was developed. The overall drag of the deck with a $200 \mathrm{~mm}$ high mesh toe board was 13\% lower than that with a solid toe board of the same height. The wire mesh toe board was thus adopted.

The static aerodynamic force coefficients of the basic erection cross-sections are shown in Figure 7 (a positive angle of incidence corresponds to the deck section rotated clockwise in a horizontally approaching wind; D and B are section depth and total width, respectively). The results are for Reynolds numbers of approximately $5 \times 10^{5}$ and smooth flow for both bridges. Table 2 shows the slopes of lift and moment for section rotations of $\pm 1^{\circ}$. These are directly related to the magnitude of vertical and torsional buffeting response (see Section 8). It is noted that the closed box of Sutong Bridge behaves similarly to a flat plate and shows a high lift slope whereas the twin-box arrangement 


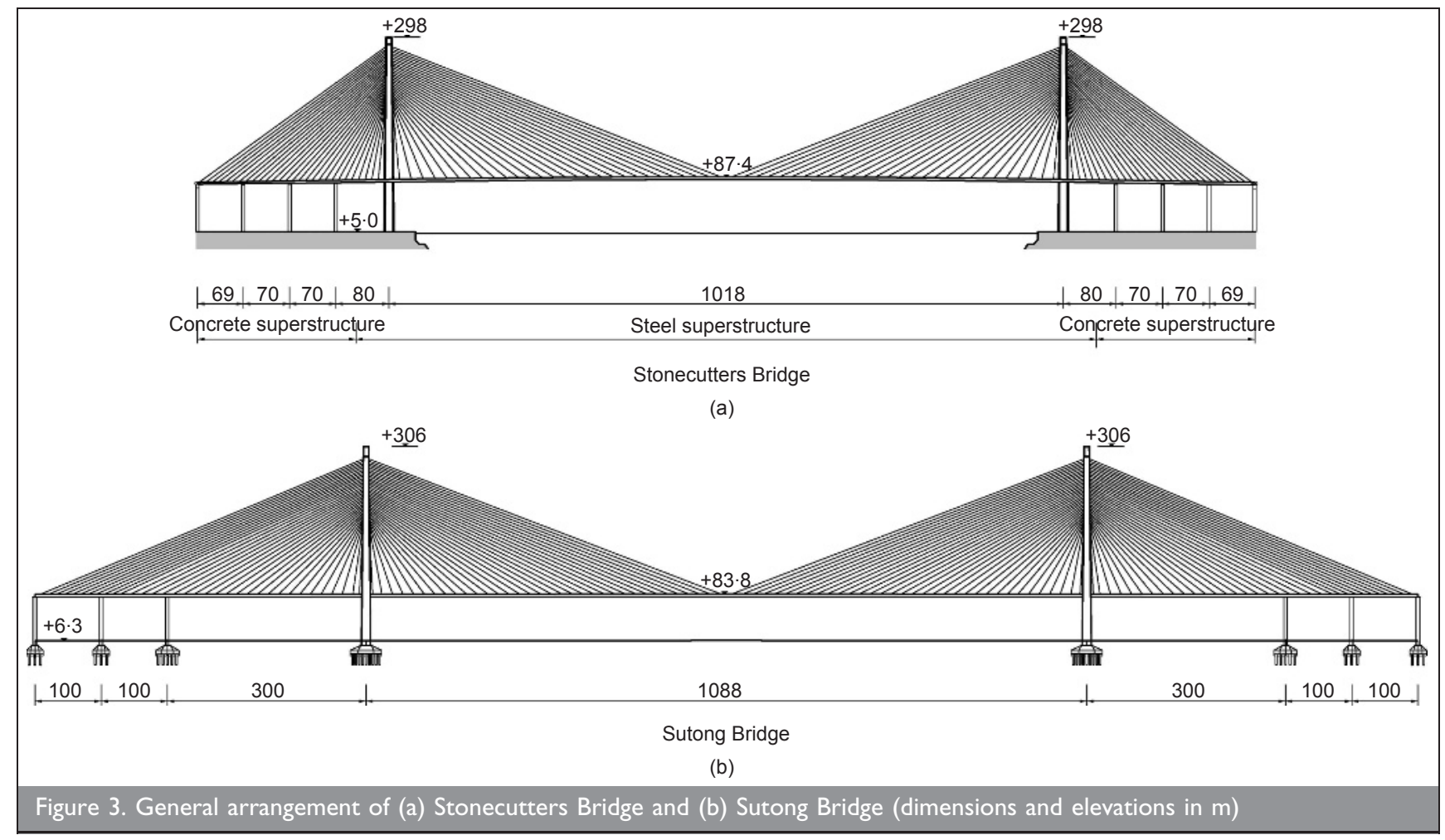

of Stonecutters Bridge exhibits significantly smaller values of both lift and moment slope. The tests were repeated with incoming turbulent flow. The results (Table 3) consistently show an increase in drag due to turbulence.

\section{STRUCTURAL PROPERTIES}

Modal properties, most important for the aeroelastic response of a structure, change continuously as bridge erection in freecantilevering proceeds. Figure 8 shows a comparison of the first two vertical (DV1, DV2) and the fundamental lateral (DL) and torsional (DT) modes of the main deck. Only the erection stages in single-sided cantilevering are considered (i.e. the initial balanced cantilevering of Sutong Bridge is omitted). Fundamentally, the two bridges exhibit similar behaviour. In fact, the first vertical and lateral frequencies are close throughout and almost identical at a maximum length of the Stonecutters cantilever. However, the second vertical mode is considerably higher for the Sutong deck, which is due to an approximately 50\% higher bending stiffness of the box girder. For the second bending mode, the flexure of the girder plays a dominant role over the stretching of the cable stay system. The difference between the two structures is even higher in the fundamental torsional frequency, with the Sutong deck twisting at about double the Stonecutters torsional frequency. This is caused, on the one hand, by a somewhat higher torsional stiffness of the Sutong girder over that of the Stonecutters grillage deck while at the same time the torsional inertia is much higher for the Stonecutters deck due to the concentration of the self-weight away from the bridge centreline. Furthermore, the Sutong A-shaped pylons have a 70\% higher torsional stiffness than the single-shaft poles of Stonecutters Bridge.

\section{AERODYNAMIC DECK STABILITY}

Aerodynamic instabilities arise from a complex dynamic interaction between changes in aerodynamic forces and the dynamic response of the structure. Aerodynamic instability of a structure can be thought of as negative damping, where the energy input per cycle of oscillation is larger than that absorbed by structural damping, thus leading to a divergent amplitude response. Instabilities are characterised by a critical wind speed above which the structure is unstable.

The instability boundary of Stonecutters Bridge deck was established by performing aeroelastic testing in the wind tunnel. The section model was spring-mounted on a rig, with stiffnesses and masses adjusted to adhere to scaling laws. For classical flutter, a coupled response of vertical and torsional modes, the critical wind speed reduces the closer the two frequencies $f_{\mathrm{T}}$ (torsion) and $f_{\mathrm{V}}$ (vertical bending) become. A range a frequency ratios $f_{\mathrm{T}} / f_{\mathrm{V}}$ was therefore tested.

Aeroelastic section model tests were not carried out for Sutong Bridge. The instability boundary was determined analytically from the results of forced-oscillation tests on the section model. The section was set into sinusoidal motion in vertical (heave) and rotational (pitch) motions, and aerodynamic forces were measured. The motion-induced forces were then expressed in terms of aerodynamic derivatives (Scanlan and Tomko, 1971) that allow computation of the instability wind speed by numerical means. Derivatives were determined for angles of incidence of $-3^{\circ}, 0$ and $3^{\circ}$.

All tests were done in smooth flow. This is the most critical condition as incoming turbulence is commonly understood to inhibit excitation. The specified required flutter boundaries for the construction stage are between $50 \mathrm{~m} / \mathrm{s}$ (at $5^{\circ}$ incidence of the mean flow) and $95 \mathrm{~m} / \mathrm{s}$ (at horizontal angle) for Stonecutters Bridge and a constant $64 \mathrm{~m} / \mathrm{s}$ for Sutong Bridge. These required flutter wind speeds were achieved throughout. Table 4 shows the test conditions including the level of damping used in the tests. Testing was only undertaken up to the equivalent fullscale wind speed required under the relevant design specifications (i.e. actual flutter wind speed was not established). 

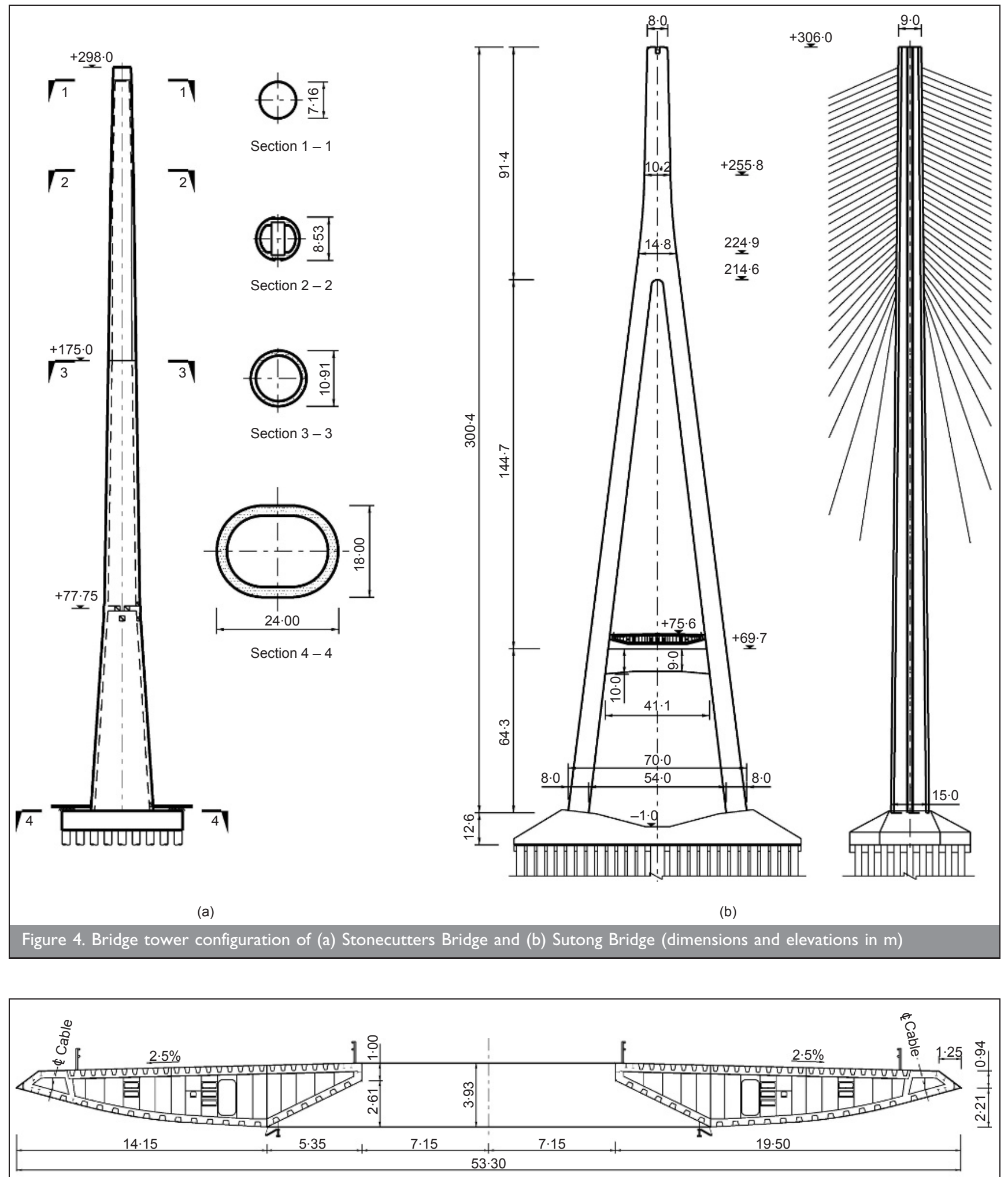

(a)

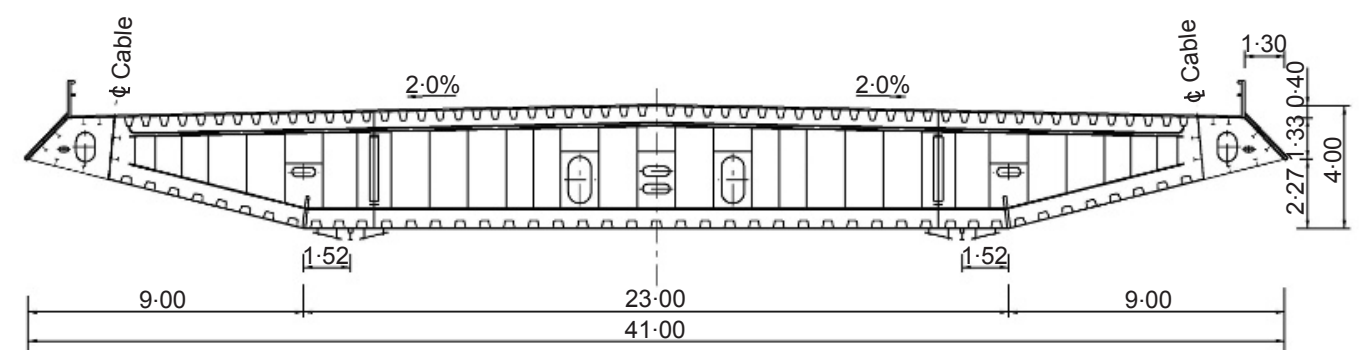

(b) 


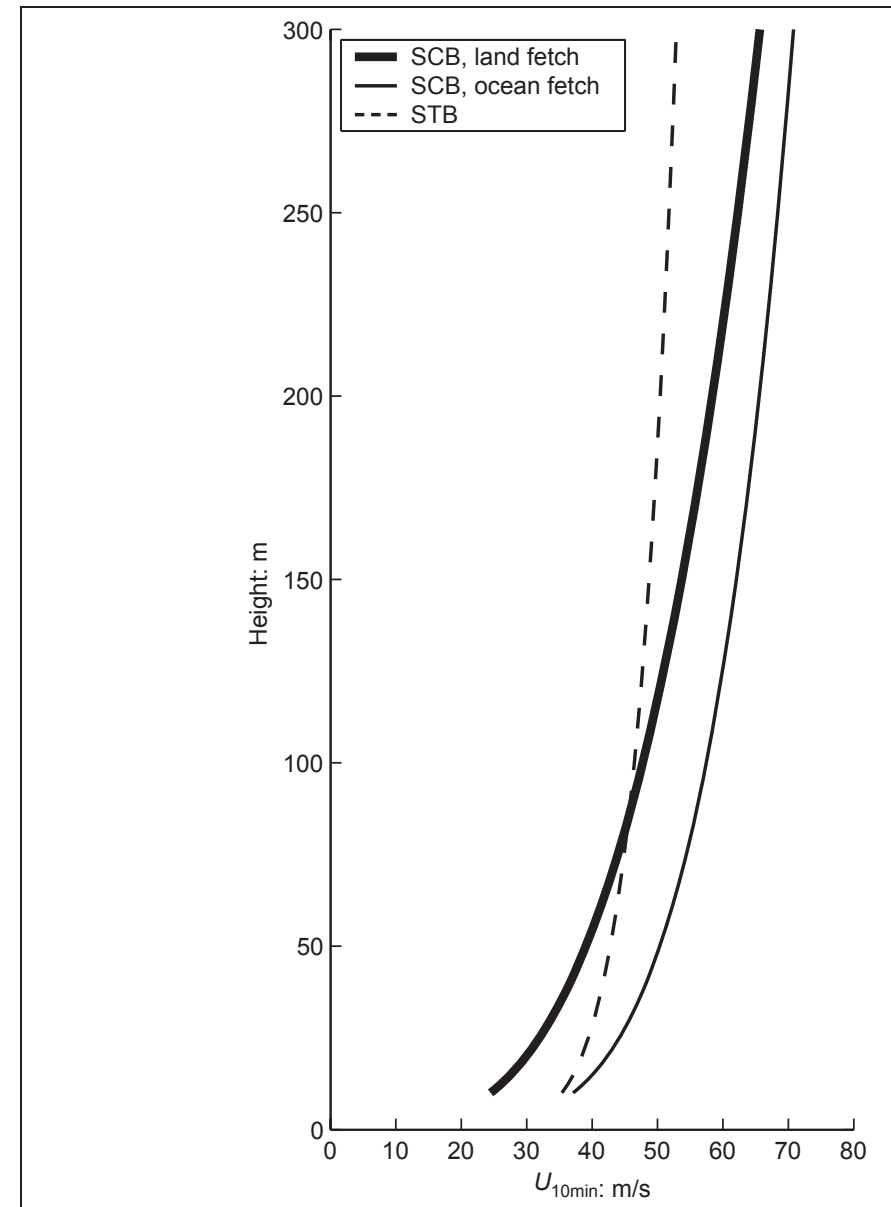

(a)

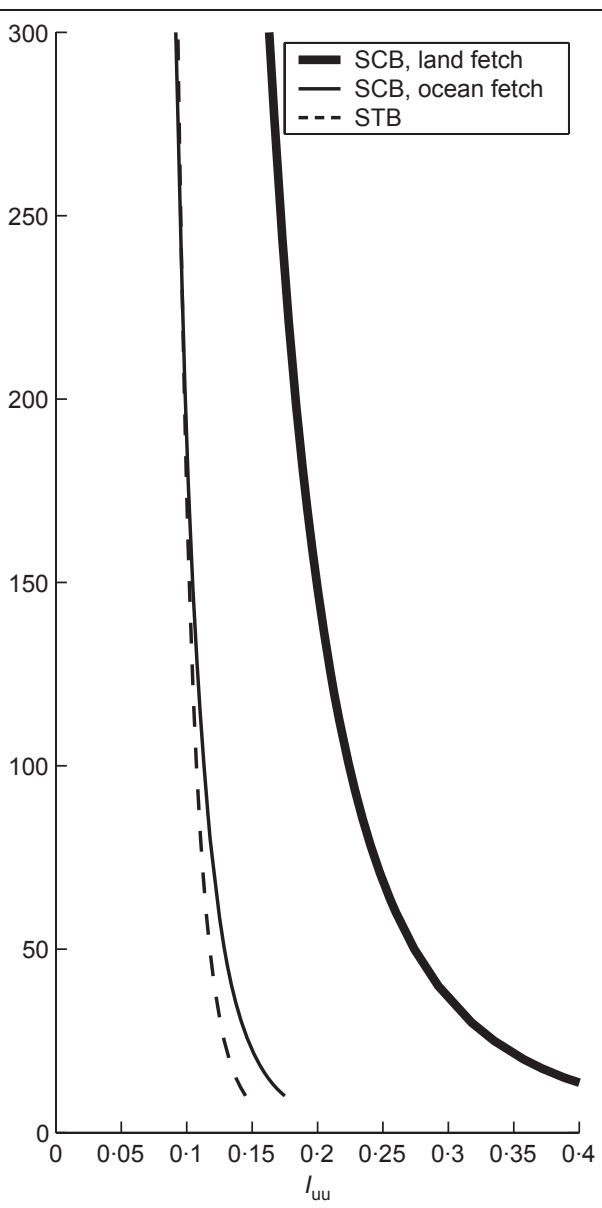

(b)

Figure 6. Design wind characteristics for Stonecutters Bridge (SCB) and Sutong Bridge (STB): (a) mean wind speed and (b) longitudinal turbulence intensity profiles

\begin{tabular}{|c|c|c|}
\hline Type of test & Stonecutters Bridge & Sutong Bridge \\
\hline Section model & Scale I:50 & Scale I:50 \\
\hline \multirow[t]{3}{*}{ Static } & With different variations (rand rail configuration, & With and without lifting gantry \\
\hline & lifting gantry and other erection equipment, guide & Turbulence $I_{\mathrm{u}}: 0$ and 0.055 \\
\hline & vanes); $\operatorname{Re}=5 \times 10^{-5}$ and $18 \times 10^{-5}$ & Angle: $-10^{\circ}$ to $+10^{\circ}$ \\
\hline Forced oscillation & No testing undertaken & Smooth flow, Angle: $-3^{\circ}, 0,+3^{\circ}$ \\
\hline \multirow[t]{3}{*}{ Aeroelastic } & Smooth flow and turbulent flow & No testing undertaken \\
\hline & Damping: $0 \cdot 15 \%$ of critical & \\
\hline & Angle: $-5^{\circ}$ to $+5^{\circ}$ & \\
\hline \multirow[t]{5}{*}{ Tower aeroelastic } & Scale I:200 & Scale I:100 \\
\hline & Two construction stages & Two construction stages \\
\hline & With/without erection equipment & With/without erection equipment \\
\hline & Various orientations & Various orientations \\
\hline & Damping: $0.16 \%$ and $0.5 \%$ of critical & Damping: $0 \cdot 5,0 \cdot 8$ and $1 \cdot 6 \%$ of critical \\
\hline \multirow[t]{5}{*}{ Full bridge aeroelastic } & Scale $1: 200$, two stages & Scale $1: 125$, two stages \\
\hline & Various orientations & Various orientations \\
\hline & With/without opposite cantilever & Turbulence $I_{\mathrm{u}}: 0,0.055$ and $0.1 \mathrm{I}$ \\
\hline & $\begin{array}{l}\text { Turbulence/speed as per ocean and land fetch } \\
\text { conditions (see Section 2) }\end{array}$ & Damping: $0 \cdot 5,0 \cdot 8$ and $1 \cdot 3 \%$ of critical \\
\hline & Damping: $0 \cdot 4,1 \cdot 3,1 \cdot 6,3 \cdot 2$ and $4 \cdot 0 \%$ of critical & \\
\hline Cable drag testing & $\begin{array}{l}\text { Scale I:I } \\
\text { Different surface patterns (smooth and with } \\
\text { dimples of different depths) }\end{array}$ & $\begin{array}{l}\text { Testing undertaken at design stage but not at } \\
\text { construction stage of the project }\end{array}$ \\
\hline \multirow[t]{5}{*}{ Cable rain/wind testing } & Scale I:I & Testing undertaken at design stage but not at \\
\hline & Different cable diameters & construction stage of the project \\
\hline & Different cable angles & \\
\hline & Rain intensity: $80 \mathrm{~mm} / \mathrm{h}$ & \\
\hline & Damping: $0 \cdot 6 \%$ log-dec & \\
\hline
\end{tabular}




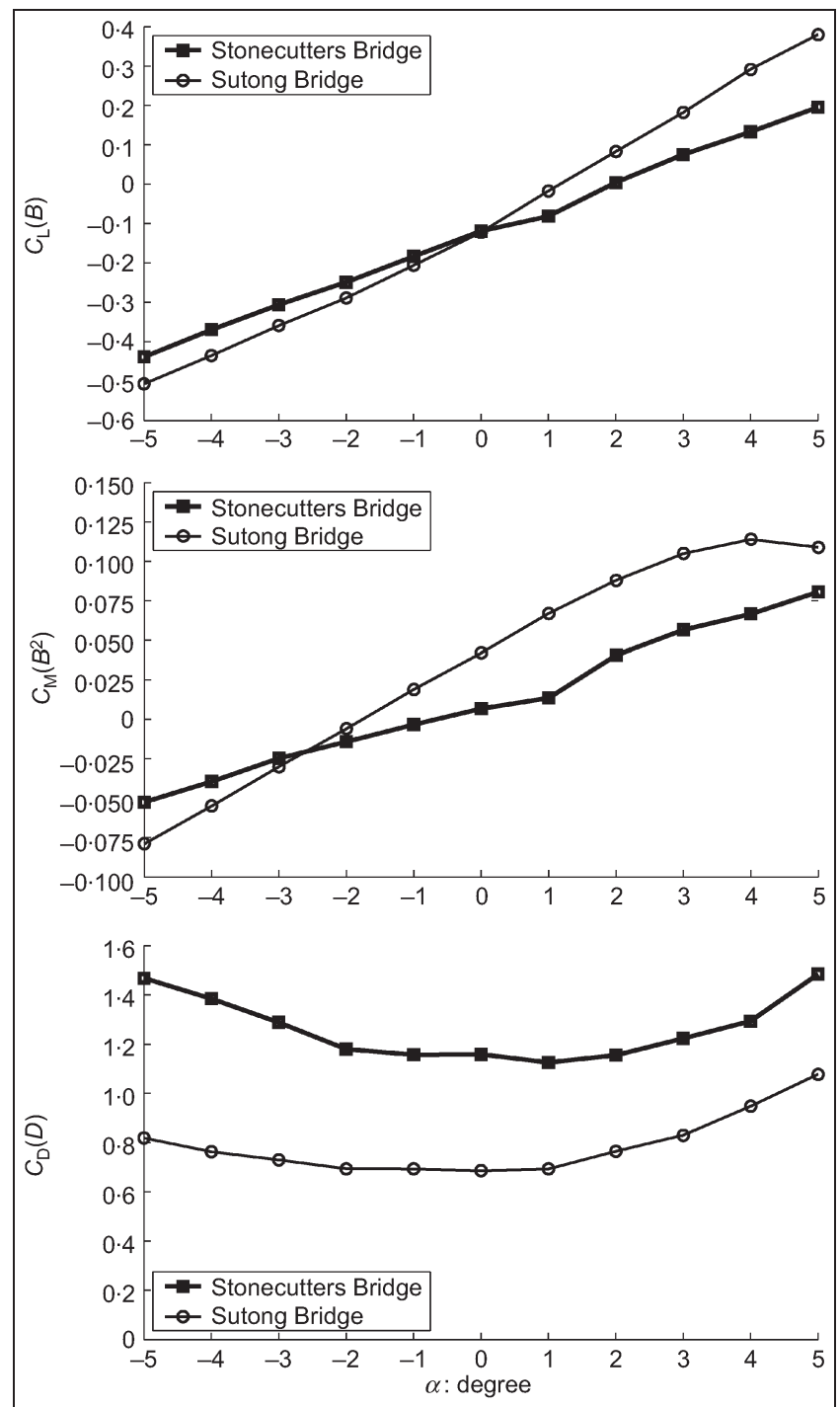

Figure 7. Section model test results (smooth flow): static aerodynamic force coefficients of deck girder in construction condition

The twin-box (vented) arrangement of the deck of Stonecutters Bridge is a major contributor to keeping the deck stable even at low frequency separations. The stability of Sutong Bridge is mostly achieved by sufficiently high torsional frequencies. Single degree-of-freedom instabilities were not observed within the critical range of wind speeds.

\section{VORTEX-INDUCED VIBRATIONS}

Shedding of vortices from bluff cross-sections in resonance with the natural frequencies of a structure can lead to unacceptable vibrations. Vortex-induced vibrations are mostly a serviceability issue since they occur at low wind speeds and are a limited amplitude phenomenon. They can, nonetheless, pose serious problems during bridge erection, the major concerns being the influence of deck vibrations on workers' comfort, on the

\begin{tabular}{|lcc|}
\hline & $\mathrm{d} C_{\mathrm{L}} / \mathrm{d} \alpha$ & $\mathrm{d} C_{\mathrm{M}} / \mathrm{d} \alpha$ \\
\hline Stonecutters Bridge & 3.0 & 0.5 \\
Sutong Bridge & 5.4 & 1.4
\end{tabular}

Table 2. Section model test results (smooth flow): slope of lift and moment coefficient curves computed for pitch angles $\alpha$ between $-1^{\circ}$ and $+1^{\circ}$ in smooth flow conditions
Increase in drag compared with smooth flow: \%

Stonecutters Bridge: turbulence

$I_{\mathrm{u}}=0.12$

Stonecutters Bridge: $I_{\mathrm{u}}=0.24$

Sutong Bridge: $I_{\mathrm{u}}=0.055$

Table 3. Section model test results: drag increase due to turbulent inflow

accuracy of survey measurements and possible parametric excitation of the tower crane. Tower crane vibrations can also be a limit-state (safety) issue.

\section{I. Tower response}

7.1.1. Stonecutters Bridge. The towers of Stonecutters Bridge are tapered, with a circular section above the deck. It was recognised that such a configuration may be prone to vortex shedding excitation. It was, however, also considered that the substantial erection equipment present at the tower (crane, man hoist, various platforms and brackets) would disturb the regularity of the vortex shedding pattern and potentially reduce the resonant response. To study the sensitivity of tower response to the erection equipment, both the fully equipped tower and the bare tower were tested.

The results for a damping of $0 \cdot 16 \%$ of critical (Table 5) indicate significant excitation for the full height tower. Table 5 shows that the different tower heights tested all have very similar Scruton numbers

\begin{tabular}{|l|l|}
\hline $\mathrm{S}$ & $S c=\frac{m \delta}{\rho D^{2}}$ \\
\hline
\end{tabular}

if they are computed with the diameter $D$ at the location of the tower top in every configuration ( $m$ is the mode generalised mass, $\delta$ is the log-dec damping and $\rho$ is air density). While the generalised mass is greater for shorter towers, the diameter is also larger. Even though the $S c$ values are similar, the amplitudes of the vortex-induced vibrations are not. The relationship between $S c$ and vibration amplitude is also less severe than usually found for closer-to-constant-diameter structures such as chimney stacks. The tapering of the section acts to reduce the severity of vortex shedding excitation as it reduces the correlation of the shedding process along the structure.

Since the equipment is present on the tower throughout, reductions could be used in the assessment of the acceptability of the tower vibrations. In the actual case of Stonecutters Bridge, this meant that a temporary pendulum tuned mass damper initially planned to be installed could be omitted, hence saving the contractor a substantial amount of money.

7.1.2. Sutong Bridge. Wind tunnel tests were conducted for two construction stages - the full-height tower with and without the tower crane and the $212 \mathrm{~m}$ high tower with the tower crane. The latter case represents the tower just before joining of the two legs.

To investigate vortex-induced vibrations, the wind tunnel test was initially conducted in smooth flow with a damping of $0.5 \%$ 

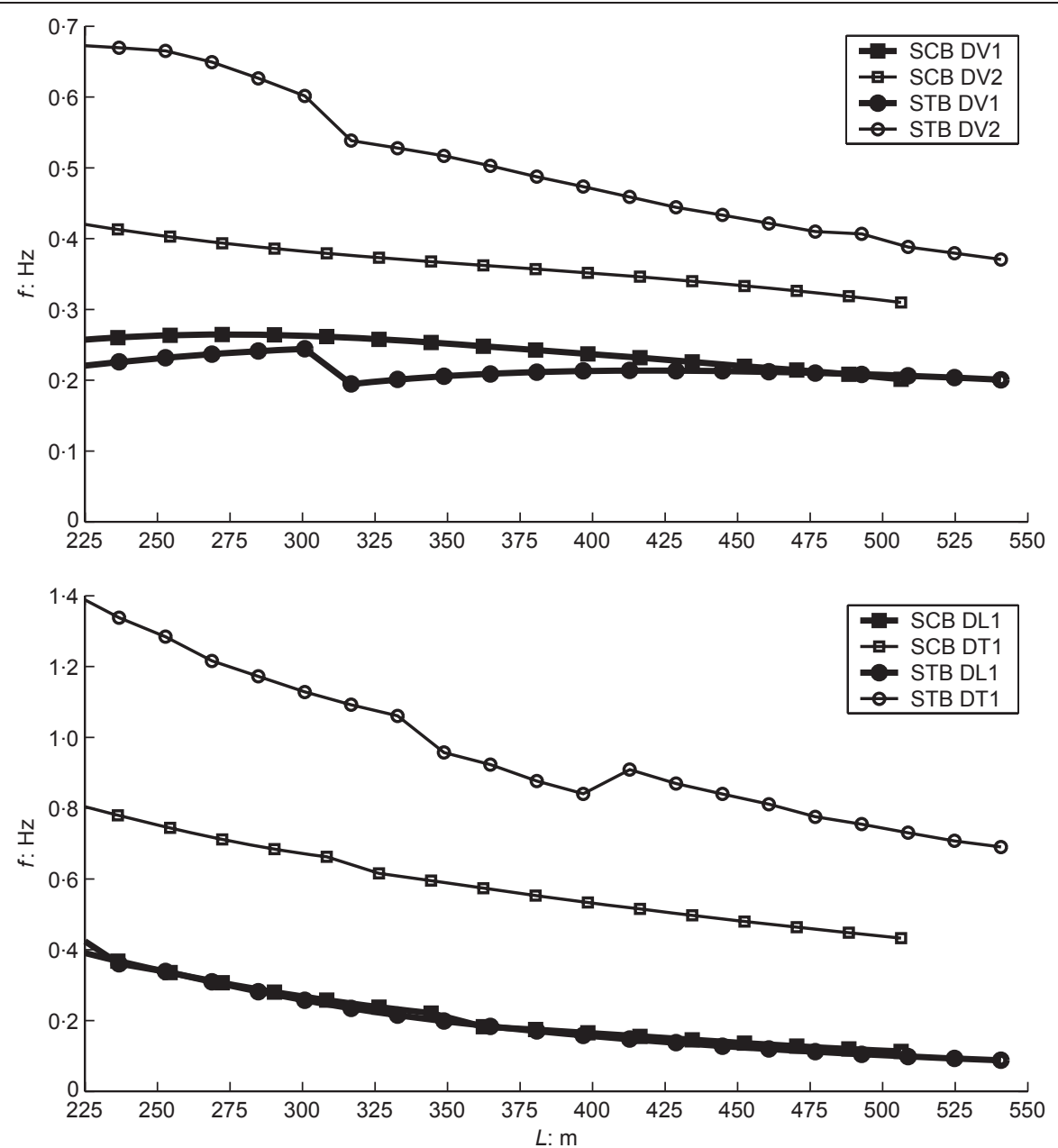

Figure 8. Natural frequencies of the deck as construction progresses. $L$ is the length of the cantilever, $D=$ deck, $V I=$ fundamental vertical, $\mathrm{V} 2=2$ nd vertical, $\mathrm{L}=$ lateral, $\mathrm{T}=$ torsional

of critical. Vortex-induced excitation was only found for the first longitudinal bending mode; the results are shown in Table 6. Amplitudes at $212 \mathrm{~m}$ are much smaller, and this is attributed to the fact that vortex shedding occurs from the two separate legs simultaneously. For longitudinal excitation, the two rectangular tower leg sections lie behind one another, which leads to a disturbance of the two shedding processes. Close to or at full height, the upper tower represents a single section with only mild tapering, giving rise to vortex-induced excitation.

Tests with 5.5\% longitudinal turbulence intensity yielded roughly half the amplitudes of those under smooth flow conditions. At the very low structural frequencies when the tower nears completion, the amplitudes correspond to accelerations below 5\% of gravity. It was hence concluded that the oscillations were acceptable and no additional tower damping was provided.

\subsection{Deck response}

7.2.1. Stonecutters Bridge. Vortex-induced vibrations of the deck were tested on an aeroelastic section model at a structural damping of $0 \cdot 2 \%$ (vertical) and $0 \cdot 4 \%$ (torsional) of critical. The tests were conducted in smooth flow, which is critical for the build-up of the vortex shedding response. Tests were first conducted without guide vanes mounted on the deck. The largest vertical bending amplitudes (root mean square (RMS)) of $120 \mathrm{~mm}$ were observed for negative angles of incidence of $-5^{\circ}$; these occurred at a reduced wind speed $U / F B=0 \cdot 55$. Amplitudes at $0^{\circ}$ were $60 \mathrm{~mm}$ in vertical bending. When guide vanes were added to the section, the response reduced significantly. The maximum amplitude then observed was $40 \mathrm{~mm}$ at $-5^{\circ}$ and too low to be measured at $0^{\circ}$. The largest torsional oscillations occurred without guide vanes between 0 and $-2.5^{\circ}$ incidence, with amplitudes of about $0 \cdot 1^{\circ}$. Again, the addition of guide vanes was found to suppress the oscillations effectively.

\begin{tabular}{|c|c|c|c|c|}
\hline & Tested $f_{T} / f_{V}$ & $\begin{array}{l}\text { Tested damping: \% of } \\
\text { critical }\end{array}$ & $\begin{array}{c}\text { Wind angle of attack: } \\
\text { degrees }\end{array}$ & $\begin{array}{l}\text { Confirmed full-scale } \\
\text { minimum critical wind } \\
\text { speed: } \mathrm{m} / \mathrm{s}\end{array}$ \\
\hline Stonecutters Bridge & $1 \cdot 20,1 \cdot 60,2 \cdot 06$ & $0 \cdot 15$ & $\begin{array}{c}0 \\
+2.5 \\
\pm 5.0\end{array}$ & $\begin{array}{l}95 \\
75 \\
50\end{array}$ \\
\hline Sutong Bridge & $2 \cdot 2 I, 2 \cdot 6 I$ & $0 \cdot 3,0 \cdot 5,0.8$ & $-3,0,3$ & 64 \\
\hline
\end{tabular}




\begin{tabular}{|lcccc} 
& & & \multicolumn{2}{c}{ Resonant RMS amplitude: mm } \\
\cline { 5 - 6 } Tower height: $\mathrm{m}$ & $\begin{array}{c}\text { Frequency of first longitudinal } \\
\text { mode: Hz }\end{array}$ & Sc & Without erection equipment & With erection equipment \\
\hline 293 & 0.17 & 12 & 150 & 35 \\
246 & 0.22 & 11 & 30 & $\sim 0$ \\
174 & 0.40 & 10 & 30 & $\sim 0$ \\
119 & 0.72 & 10 & $\sim 0$ & $\sim 0$
\end{tabular}

Table 5. Vortex-induced vibrations of the Stonecutters Bridge free-standing tower at a damping of $0 \cdot 16 \%$ of critical

7.2.2. Sutong Bridge. Vortex-induced vibrations of the Sutong Bridge deck were studied only with guide vanes fitted.

Measurable amplitudes were observed only for the first torsional mode and only in smooth flow at $+3^{\circ}$ of angle of attack. The RMS amplitudes were $0 \cdot 05^{\circ}$, using an intrinsic damping of $0 \cdot 3 \%$ of critical.

\section{BUFFETING RESPONSE}

Buffeting is a pseudo-random dynamic response of a structure caused by fluctuating aerodynamic forces that arise from velocity changes of a gusty wind. These gusts are due to the turbulent nature of the atmospheric boundary layer. The atmospheric boundary layer exhibits an exponential mean wind speed profile overlain on which are transient velocity effects caused by the turbulence generated due to friction between the air and terrain surface.

Buffeting response of the towers was not found to be a problem. Amplitudes at low (operational) wind speeds were low, and even at high wind speeds did not pose a threat to structural integrity. For deck and cables, however, careful analysis of the magnitude of buffeting response is critical. To assess the structural adequacy of such components, accurate buffeting predictions were required because over-conservative results would likely have meant additional costs for certain strengthening measures.

The current study relied on a combined approach of wind tunnel testing and numerical buffeting simulations (Morgenthal and Sham, 2006). The aeroelastic tests of tower and deck erection stages were conducted in a boundary layer wind tunnel to reproduce the desired turbulent wind field. Erection equipment was modelled to represent accurately the situation during erection; in particular, the lifting gantry located at the tip of the cantilever added substantial drag and hence increased the lateral response. Examples of the models are shown in Figure 9.

Upon assembly, the modal representation of the models was carefully checked against the targets. The targets had been formulated based on modal analysis of the computer models and on preliminary analytical buffeting analyses that indicated the modal contribution to the buffeting response. Any mode that contributed more than $10 \%$ to the peak buffeting response in any direction was to be accurately represented by the model. Both the natural frequency and the mode shape were then shown to be in sufficiently close agreement. It was found that deck lateral, deck vertical, deck torsional and tower lateral fundamental directional modes were required. Furthermore, the second vertical deck mode was found to contribute significantly and thus also had to be included.

The mean and peak dynamic buffeting responses were measured and used to validate a numerical buffeting simulation model. The numerical model was based on a three-dimensional finiteelement model of the bridge; this approach (Morgenthal et al., 2005) allows for detailed modelling of all structural features including the aerodynamic properties of the different members. The model was effectively exposed to a theoretically derived wind event, which satisfied the stochastics of the prescribed turbulent wind field data. The transient response of the structure was calculated and analysed to determine design forces and displacements. The results of the numerical analyses agreed very well with the results of the wind tunnel testing.

For Sutong Bridge, the maximum balanced cantilever condition was critical to some items, namely the rotational restraint provided for the deck at the tower. The bridge was built in balanced cantilevering until reaching closure to the backspan deck, which occurred at $157 \mathrm{~m}$ long cantilevers. This situation, however, is similar to more standard medium-span bridges and is therefore not discussed further here. The lengths of the bridge cantilevers before installation of the closing segments were $506 \mathrm{~m}$ for Stonecutters Bridge and $541 \mathrm{~m}$ for Sutong.

\section{I. Vertical response}

The critical condition for vertical buffeting response during cantilevering erection is the stage when the new segment has been installed but the corresponding set of main span stay cables has not yet been stressed. In this situation the dead load of the cantilevering new segment induces large hogging in the bridge girder. These negative bending moments are subsequently reduced by cable stressing, which effectively takes much of the new segment weight. The overhanging situation is almost always critical to the girder design. Furthermore, the front set of stay cables to the previously installed segment is heavily

\begin{tabular}{|lccccc|}
\hline & Frequency of first longitudinal & & & \multicolumn{2}{c|}{ Resonant RMS amplitude: $\mathrm{mm}$} \\
\cline { 5 - 5 } Tower height: $\mathrm{m}$ & mode: $\mathrm{Hz}$ & Sc & Without erection equipment & With erection equipment \\
\hline 306 & 0.13 & 39 & 457 & 394 \\
212 & 0.25 & 42 & Not measured & 52 \\
\hline
\end{tabular}




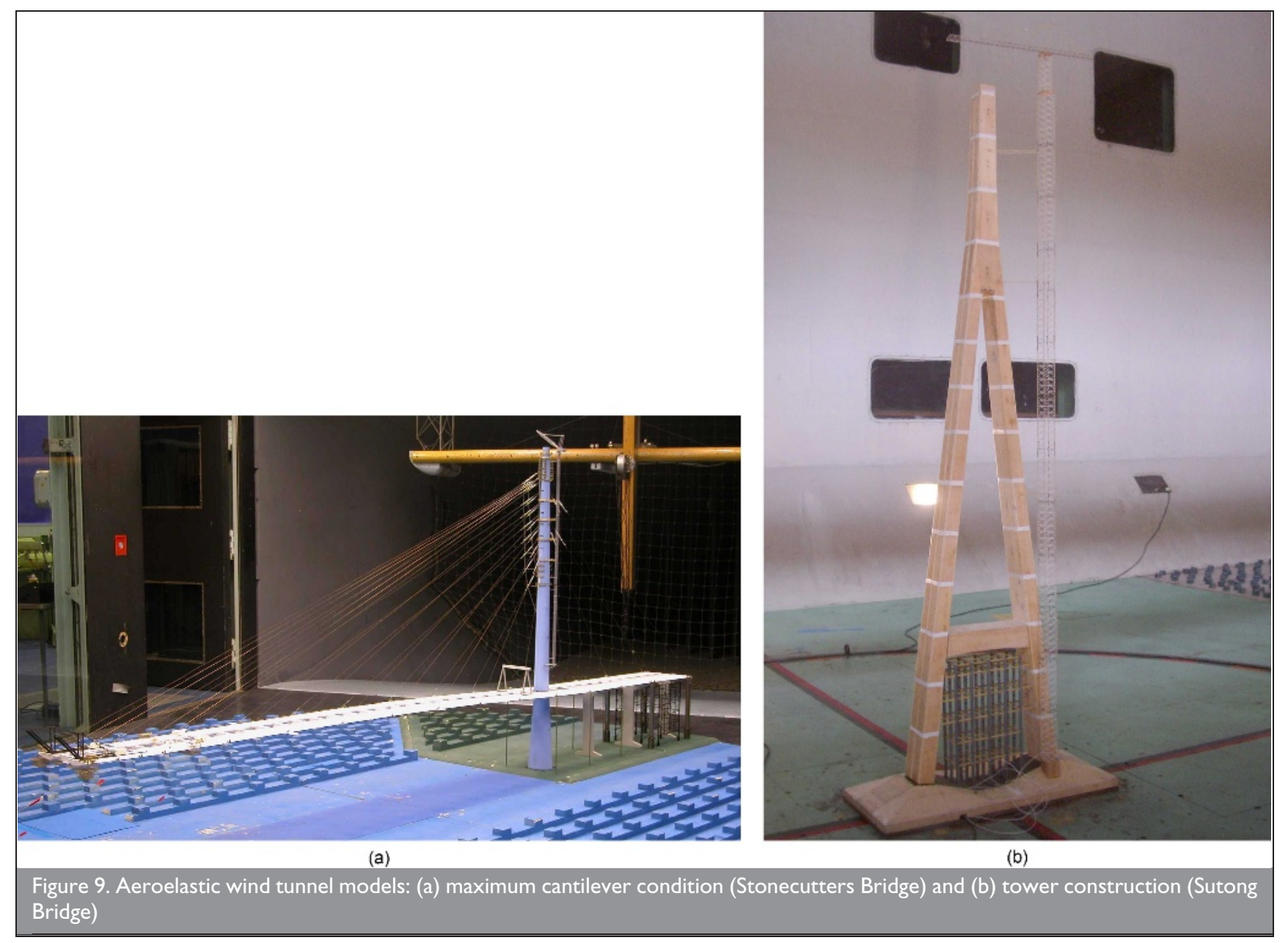

stressed. It is for this reason that the downward component of the buffeting excitation becomes critical as it increases hogging in the girder and the stay forces.

A structural damping of $0.5 \%$ of critical was used for the analyses. Figure 10 shows the distribution of peak bending moments in the girder and the respective cable forces. Clearly, the critical condition for Stonecutters Bridge is the highturbulence land fetch wind, which induces significantly higher demand in the structure than the ocean fetch wind. From the shape of the bending moments it is also clear that the second vertical deck mode contributes significantly. Sutong Bridge, also exposed to sea fetch type wind of low turbulence, shows a higher demand than the corresponding Stonecutters wind. This is due to the higher susceptibility of the cross-section to vertical buffeting, as manifested in the lift and moment coefficient slope (see Section 4). In the event, however, it was Stonecutters deck that did not have sufficient capacity for the last stages (longest cantilevers) with full buffeting because of the relatively low capacity for negative bending moments (buckling of the bottom chord). Special measures (ballast) had to be introduced to reduce the static hogging moments in the erection condition when a new segment was being lifted (see Morgenthal et al. (2010)).

The peak cable forces of Stonecutters Bridge between ocean and land fetch scenarios are relatively close, which is due to the static wind component contributing more to the cable forces than to the bending moments in the girder, such that the higher mean wind speed in ocean fetch winds (see Section 2) can compensate the higher dynamic component of the land fetch response. The cable forces in vertical buffeting are then smaller for Sutong Bridge because of the smaller mean wind speed compared with the Stonecutters ocean fetch.

Displacement results for the tip of the cantilever are shown in Table 7. These displacements are very large for such long cantilevers.

\subsection{Lateral response}

While the basic characteristics of the lateral response of the two bridges are relatively similar, the way the forces are carried to the foundations is very different. First, the twin-deck arrangement of Stonecutters Bridge leads to a Vierendeel-type transverse bending behaviour where the lateral bending moments are carried both by bending of the longitudinal and cross-girders as well as by a differential axial force between the longitudinal girders. The deck is also laterally stiffer than the Sutong deck. Second, the tower only provides restraint for lateral forces by a bearing. The Sutong Bridge girder remains almost free of axial forces due to lateral buffeting, but is restrained by the tower not only laterally but also in its rotation about the vertical axis. This restraint is realised through a series of temporary fixing cables between the deck and tower cross-beam. The remaining lateral bending moment in the girder not taken by these restraints is carried to the backspans and resisted by transverse forces on the backspan piers. This effect is important to the lateral buffeting behaviour of Sutong Bridge, particularly during cantilevering as the buffeting wind effects 


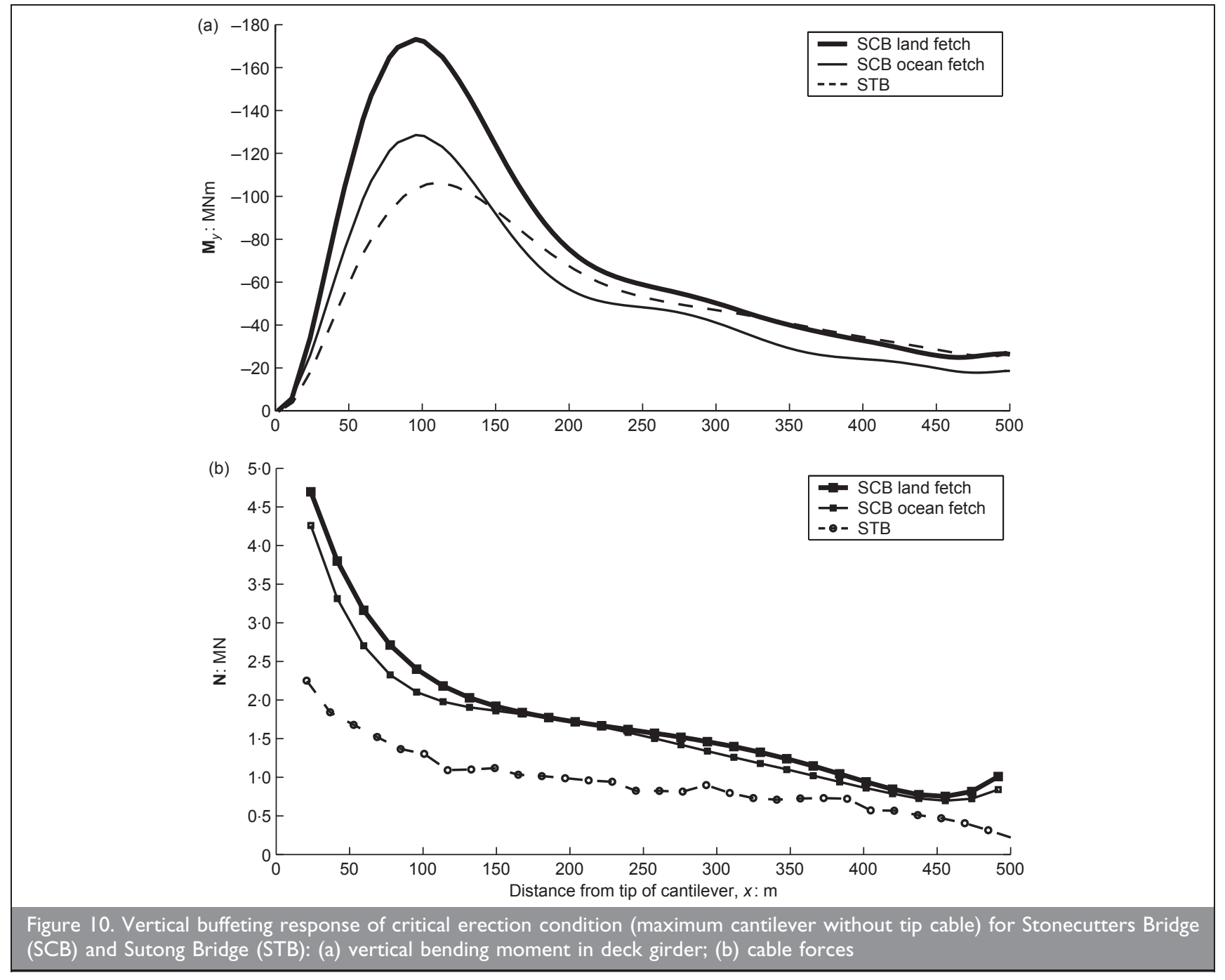

on the sidespan tend to counteract those of the main span through modal coupling and hence reduce the dynamic buffeting response. This reducing effect is essentially absent in Stonecutters Bridge, which therefore experiences a greater dynamic amplification as manifested in the ratio between peak and mean lateral deflections (see Table 7).

\section{CABLE VIBRATIONS}

Vibrations of stay cables are a particular problem in cable-stayed bridges. The topic has received a great deal of attention in recent years (e.g. Caetano, 2007), mainly due to major vibration issues related to rain/wind-induced excitation phenomena. To counteract such cable oscillations originating from the instability of rivulets on cable perimeters subject to wind, the cable sheeting on both Stonecutters Bridge and Sutong Bridge has a dimpled surface texture. Special aeroelastic 1:1 scale rain/wind wind tunnel tests have confirmed the effectiveness of the texture.
Permanent cable dampers (which are part of the final design) were not present during erection and it was clear that vibrations could occur due to galloping, vortex shedding and internal resonance at a wide range of service wind speeds and in almost any cable. Of most concern was banging of a cable against its guide tube, with the potential to damage the cable. A robust approach was selected where the cables were fixed to the exit of the tube by wedges (Figure 11). This was found to be very effective as it also adds damping through friction effects. Pretensioned steel tie-down cables were also fixed to some cables (Figure 11). This provided stiffness to the main cable and hence raised the frequency; this was found to affect the vibration characteristics favourably, particularly of higher modes.

\section{I0. CONCLUSIONS}

A comparison of the aerodynamic properties and aeroelastic behaviour during erection of the world's two longest span

\begin{tabular}{|c|c|c|c|c|}
\hline & \multicolumn{2}{|c|}{ Vertical displacement: $\mathrm{mm}$} & \multicolumn{2}{|c|}{ Lateral displacement: $\mathrm{mm}$} \\
\hline & Mean & Peak & Mean & Peak \\
\hline Stonecutters Bridge, land fetch & 230 & 3210 & 970 & 2980 \\
\hline Stonecutters Bridge, ocean fetch & 350 & 2550 & 1370 & 3220 \\
\hline Sutong Bridge & 240 & 1520 & 2440 & 4930 \\
\hline
\end{tabular}




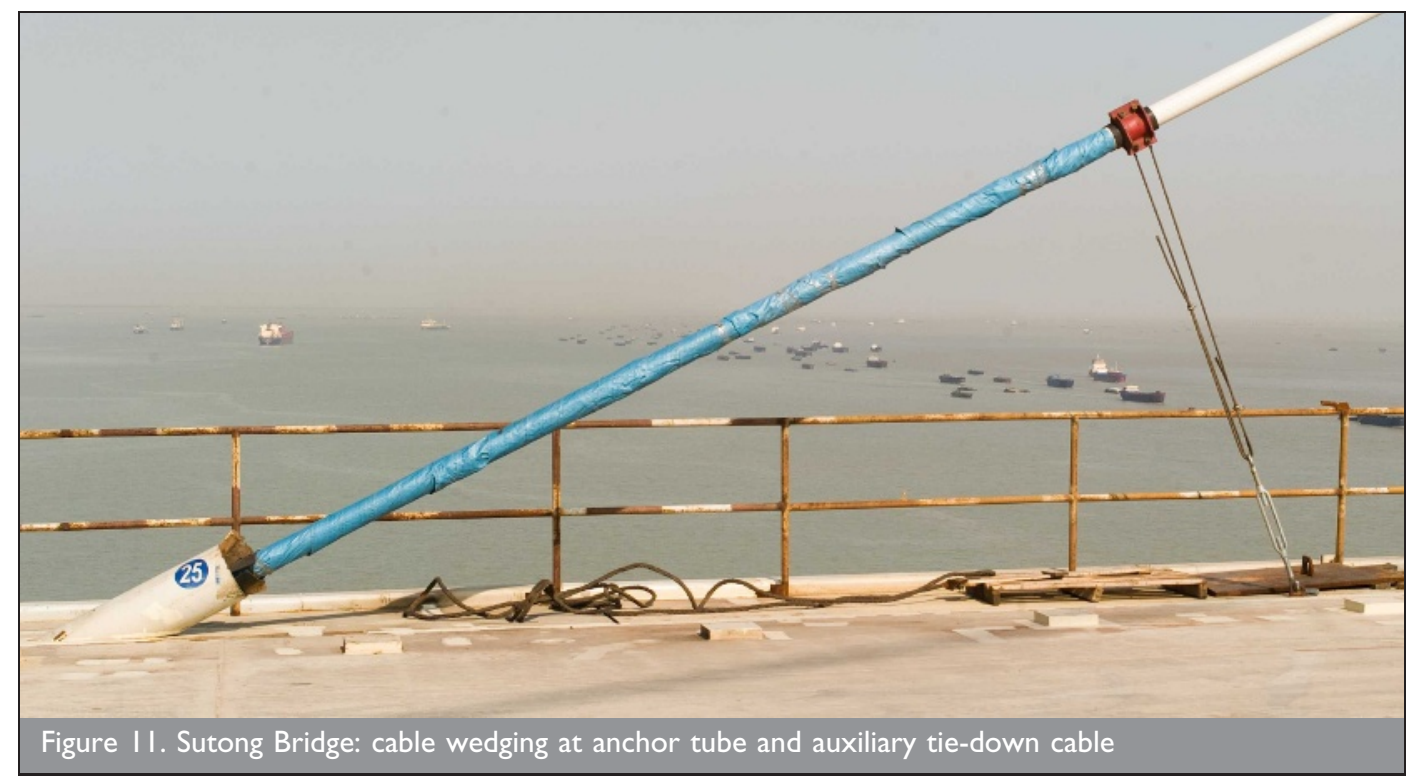

cable-stayed bridges has been presented. Although the bridges are similar in span length and construction methodology, this study has highlighted significant differences in many respects. These are mostly related to different wind characteristics on site, very different deck cross-sections and different overall structural configurations. The effect of these aspects on the dynamic behaviour of the bridges during construction was discussed. This work also revealed that some fundamental properties (e.g. the fundamental vertical vibration modes and related buffeting effects) were very similar. Since wind effects are a major design criterion for long-span bridges, the differences and similarities discussed here provide a valuable insight into the aerodynamic characteristics of a new generation of cable-stayed bridges.

\section{ACKNOWLEDGEMENT}

The authors wish to thank all those involved for their helpful contributions.

\section{REFERENCES}

BSI (British Standards Institution) (1978) BS 5400: Steel, concrete and composite bridges. Part 2: Specification for loads. BSI, London.

Caetano E (2007) SED 9: Structural engineering documents - cable vibrations in cable-stayed bridges. International Association for Bridge and Structural Engineering, Zurich, Switzerland.

CCHPDRI (China Communications and Highway Planning Design and Research Institute) (2004) JTG/T D60-01-2004: Wind-resistant design specification for highway bridges.

China Communication Press, Beijing.

GHKSAR (Government of the Hong Kong Special Administrative Region) (2006) Structures Design Manual, 3rd edn. Highways department, GHKSAR, Kowloon, Hong Kong.

Morgenthal G and Sham R (2006) Erection stage buffeting analyses of Stonecutters Bridge. Proceedings of HKIE International Conference on Bridge Engineering - Challenges in the 21st Century, Hong Kong. Hong Kong Institution of Engineers.

Morgenthal G, Kovacs I and Saul R (2005) Analysis of aeroelastic bridge deck response to natural wind. Structural Engineering International 15(4): 232-235.

Morgenthal G, Sham R and West B (2010) Engineering the tower and mainspan construction of Stonecutters Bridge. ASCE Journal of Bridge Engineering 15(2): 144-152.

Scanlan RH and Tomko JJ (1971) Airfoil and bridge deck flutter derivatives. CE Journal of Engineering Mechanics 97(6): 1717-1737.

\section{What do you think?}

To discuss this paper, please email up to 500 words to the editor at journals@ice.org.uk. Your contribution will be forwarded to the author(s) for a reply and, if considered appropriate by the editorial panel, will be published as discussion in a future issue of the journal.

Proceedings journals rely entirely on contributions sent in by civil engineering professionals, academics and students. Papers should be 2000-5000 words long (briefing papers should be 1000-2000 words long), with adequate illustrations and references. You can submit your paper online via www.icevirtuallibrary.com/content/journals, where you will also find detailed author guidelines. 